\title{
Gestión de personas en la Administración Central del Estado y asesoría de la Dirección Nacional del Servicio Civil
}

\author{
Nicollete Molina \\ Universidad de Chile
}

\section{Resumen}

El presente estudio analiza la asesoría brindada por la Dirección Nacional del Servicio Civil (DNSC) y estudia como dicha asesoría influye en la consolidación de buenas prácticas laborales en los servicios públicos de la administración central (SPAC). De acuerdo a la indagación efectuada, se ha podido constatar que la DNSC ha logrado constituirse como una agencia especializada en materias para la gestión de las personas en el Estado. Sin embargo, el modelo de asesoría y gestión, presenta aspectos que requieren atención. Entre ellos, los contextos internos de los SPAC que fueron asesorados tuvieron mayor fuerza a la hora de implementar o no, reformas en lo relativo a gestión de personas; La estrategia de gestión de la DNSC, ha respondido a los contextos políticos, generando un apilamiento de iniciativas y reformas en desarrollo de personas; Existen debilidades en la planificación y objetivos de la DNSC, los niveles de logro en la actualidad son parciales y con una evidente disparidad en los niveles de avance de cada SPAC. En suma, se evidenció que el trabajo desarrollado en materias de políticas de desarrollo de personas ha sido parcial, siendo un desafío para la DNSC asumir una labor de rectoría en la materia.

Palabras clave: Dirección Nacional Servicio Civil, Desarrollo de Personas, Gestión Pública.

People management in the Central Administration of the State and advice of the National Directorate of Civil Service

\begin{abstract}
The present study analyzes the advice provided by the National Directorate of Civil Service (NDCS) and studies how this advice influences the consolidation of good labor practices in public services of the central administration (PSCA). According to the investigation carried out, it has been verified that the NDSC has succeeded in establishing itself as an agency specialized matters of people management in the state. However, the advisory and management model presents aspects that require attention. Among them, the internal contexts of the PSCA that were advised has more strength at the time of implement or not, reforms related to people management. The management strategy of the NDCS has responded to political contexts, generating a stacking of initiatives and reforms in people development. There are weaknesses in the planning and objectives of the NDCS, levels of achievement are currently partial and with an evident disparity in the levels of progress of each PSCA. In summary, it was evidenced that the work developed in subjects of policies of people development has been partial, being a challenge for the NDCS to assume a role of rectory in the matter.
\end{abstract}

Keywords: National Directorate of Civil Services, People Development, Public Management.

*Dirección de correspondencia [Correspondence

address]: Nicollete Molina, Universidad de Chile

E-mail: nicollettemolina@gmail.com 


\section{Introducción}

Es evidente que la gestión de personas juega un rol central en la gestión exitosa de una organización. En el caso del sector público, contar con personas idóneas para la implementación de políticas públicas y que cumplan las expectativas y den respuestas efectivas a una ciudadanía cada vez más informada, empoderada y demandante de sus Gobiernos, es una tarea fundamental. Es por ello, que colocar el foco en un Estado mejor, más eficiente y eficaz, implica necesariamente entender la Gestión de Personas como un componente clave de la Gestión Pública. Por lo que, el Servicio Civil conceptualizado como un "sistema de articulación del empleo público mediante el que determinados países garantizan, con enfoques, sistemas e instrumentos diversos, ciertos elementos básicos para la existencia de administraciones públicas profesionales" (Longo, 2001: 6), es un elemento central para generar dicha capacidad de acción estatal. El Informe sobre la situación del servicio civil en América Latina (2006) elaborado por el Banco Interamericano de Desarrollo (BID), concluía en ese entonces que el Servicio Civil de la región estaba atravesando por una transición en la mayoría de países de Latinoamérica. Una década después de la medición realizada por el BID, en el documento titulado "Al Servicio del ciudadano: Una década de reformas del Servicio Civil en América Latina" (2014), dicho organismo concluye que existe un progreso alentador en términos de modernización del Servicio Civil en la región, aunque esta se mantiene en un nivel relativamente bajo. Sin embargo, Chile muestra uno de los procesos de reforma institucional del Estado más largos, estables y creativos en lo relativo a su Servicio Civil (Cortázar, 2011). De acuerdo a los antecedentes expuestos, es que se hace relevante entonces analizar ¿en qué medida la DNSC ha logrado constituirse como una agencia especializada en materias para la gestión de las personas en el Estado?. Si bien el fortalecimiento en la práctica de la entidad, como concluye el informe del BID (2014), fueron factores que contribuyeron para que Chile transitara en una década de una etapa de formalización a otra donde es posible asegurar la calidad del Servicio Civil, se hace imprescindible revisar los mecanismos que permiten la articulación entre el Estado y los funcionarios públicos.

\section{Objetivos, Alcances y Aspectos Metodológicos del Estudio}

El principal objetivo de esta investigación es realizar una revisión de la asesoría brindada por la
Dirección Nacional del Servicio Civil (DNSC) y estudiar como dicha asesoría influye en la consolidación de buenas prácticas laborales en los servicios públicos de la administración central (SPAC). Sin embargo, entendiendo que el tema de este estudio es bastante extenso, se dejan establecidos el alcance de la presente investigación, ya sea por razones prácticas o del objetivo del estudio: Se estudia la gestión de la Sub Dirección de Desarrollo de Personas (SDDP) de la DNSC y su contribución en la implementación de buenas prácticas laborales en los Servicios Públicos, no la gestión desarrollada por la Sub Dirección de Alta Dirección Pública (SDADP) o el Consejo de Alta Dirección Pública (CADP), todas pertenecientes a la DNSC.

La investigación se desarrollará con un enfoque cualitativo de carácter inductivo e iterativo, mediante el desarrollo de etapas de tipo exploratoriodescriptivo (Sampieri et al., 2006).

La hipótesis emergente de trabajo fue flexible, contextual y adaptable a los cursos que en su desarrollo fue tomando el estudio de caso (Sampieri et al., 2006). Sin embargo y de acuerdo a la inmersión inicial realizada en el campo de análisis, se indujo preliminarmente como hipótesis que orientó este estudio, que la asesoría que brinda la DNSC en gestión de personas permite la creación de políticas laborales en los SPAC, sin asegurar el desarrollo sostenido y sistemático de reformas relativas a la carrera funcionaria en el Estado.

El procesamiento de la información se efectuó a través del análisis de contenido. La parte del fenómeno que fue estudiado, en detalle corresponde a las entrevistas. Considerando la gran cantidad de datos potenciales, se utilizó una dirigida a expertos: Autoridad y Altos Directivos de la DNSC y una muestra intensiva, con elección de casos de un perfil similar y representativos de un segmento, en este caso, Jefaturas y analistas de unidades de gestión de personas de las respectivas Subsecretarias de los Ministerios seleccionados. Se realizaron entrevistas estructuradas y semi estructuradas a diferentes actores, tanto de la DNSC como de los Ministerios y Subsecretarias seleccionadas. La selección se basó en una elección de informantes calificados y que estuvo dirigida a expertos: Autoridad y Altos Directivos de la DNSC y una muestra intensiva, con elección de casos de un perfil similar y representativos de un segmento de la población del estudio, siendo informantes estratégicos, Jefaturas y analistas de unidades de Gestión de Personas de las respectivas Subsecretarias de los Ministerios seleccionados. Los entrevistados fueron seleccionados sobre la base de identificar aquellos informantes estratégicos que poseían antecedentes e información que fue útil para descubrir hechos, especificar característi- 
cas, clarificar apreciaciones y opiniones preliminares que se tenían sobre el caso de estudio y conocer cómo se manejan las operaciones desempeñadas en las diversas dependencias de gestión y desarrollo de personas. Para ello, las entrevistas se aplicaron en todos los niveles: alta directiva, gerenciales, jefaturas y de colaboradores, lo que permitió obtener una mirada integral del caso de estudio desde los diferentes niveles en los que opera el desarrollo de políticas de personas. De acuerdo a lo anterior, es que para realizar el muestreo se tuvo como objetivo realizar una indagación en profundidad con personas y organizaciones que ayudaran a entender el fenómeno de estudio y a responder las preguntas de investigación. De este modo, se tuvo en consideración, en primer lugar, la capacidad operativa de recolección y análisis, seguido del entendimiento del fenómeno y, luego, la naturaleza del fenómeno bajo análisis. La selección de Ministerios y Subsecretarías que conforman los informantes estratégicos, se fundamenta y estructura, en el grupo receptor de la gestión realizada por la DNSC, el cual se compone de Ministerios, Subsecretarias, servicios públicos dependientes y relacionados y que constituyen la administración central del Estado (ACE). Con ello, se toma como base la propia clasificación utilizada por la SDDP de la DNSC (ver tabla 1), la cual considera para su distribución y categorización, la agrupación por sectores, por lo que la elección de una determinada Subsecretaría se fundamentó en la viabilidad de poder tener una mirada global sobre las diversas funciones ejecutadas en los SPAC de acuerdo al sector productivo al que pertenece cada Ministerio.

En consideración a la capacidad operativa de recolección y análisis, es que la selección de unidades se realiza sólo a nivel de Subsecretarías de cada Ministerio, dada la mirada holística y general que pueden aportar al fenómeno de estudio. Para la selección de sólo una Subsecretaría por Ministerio, se identificó aquella más representativa de la gestión del respectivo Ministerio, o bien, la que concentra en mayor medida la gestión relacionada con materias de recursos humanos, siendo excluidas otras Subsecretarías del mismo Ministerio, sus servicios relacionados y dependientes, lo anterior, dada la capacidad real de recursos y de tiempos con los que se dispuso. A su vez, se definió un determinado número de unidades de análisis considerando que el número de casos seleccionados permitió entender el fenómeno de estudio (ver tabla 2).

Respecto al análisis de contenido, las siguientes fueron las categorías sobre las cuáles se realizó el análisis de contenido:

- Cambios en la Gestión de Personas y existencia o no de nuevas prácticas institucionales.

- Desarrollo de nuevas capacidades en la Gestión de Personas.

- Impacto de los ciclos políticos en la implementación de buenas prácticas laborales.

- Influencia de la cultura organizacional en la consolidación de buenas prácticas laborales.

- Valoración integral hacia la DNSC en aspectos como estructura, recursos conocimientos y capacidad de gestión.

Para llevar a cabo el análisis de contenido se observó la frecuencia de aparición de las categorías recientemente indicadas, utilizando para ello, un sistema de frecuencia ponderada (Bardin, 2002). Para facilitar el juicio del grado de intensidad a codificar (Osgood et al., 1957) las siguientes son las subcategorías que se utilizaron para llevar a cabo este estudio:

- Favorable: Todas aquellas frases que de alguna manera defendieron, no pusieron en duda la credibilidad, apoyaron y secundaron una postura determinada de la DNSC.

- Desfavorable: Todas aquellas frases que de alguna manera pusieron en duda la credibilidad, no apoyaron ni secundaron, desvaloraron, contradijeron o negaron lo establecido por una persona, institución u organización relacionada con la DNSC.

- Neutro: Las frases cuyos objetivos no enunciaron ninguna crítica, ya fuera favorable o desfavorable frente a la temática que abordaban.

\section{Análisis conceptual del Servicio Civil y Gestión de Personas en la Administración Pública Chi- lena}

Para los objetivos de este estudio de caso se debe tener en consideración que la expresión de Servicio Civil, es frecuentemente utilizada con significados diferentes (Longo, 2001), ya sea desde una perspectiva normativa, como aquella parte del empleo público regulada por normas de derecho público, diferentes de las leyes civiles o laborales que regulan el resto del trabajo por cuenta ajena en la sociedad, se habla entonces de "función pública", regida por un estatuto propio, distinto del que se aplica al empleo común (Palomar, 2000). Otra forma, nos llevaría a 
Tabla 1: Distribución de Ministerios por Sector efectuada por la Dirección Nacional del Servicio Civil

\begin{tabular}{|c|c|c|c|}
\hline SECTOR & MINISTERIOS & No DE SERVICIOS & No DE SECTOR \\
\hline ECONÓMICO & $\begin{array}{l}\text {-Hacienda } \\
\text {-Economía, Fomento y Turismo }\end{array}$ & 26 & 1 \\
\hline $\begin{array}{l}\text { CIUDAD, PATRIMONIO } \\
\text { E INFRAESTRUCTURA }\end{array}$ & $\begin{array}{l}\text {-Vivienda y Urbanismo } \\
\text {-Bienes Nacionales } \\
\text {-Obras Públicas }\end{array}$ & 31 & 2 \\
\hline POLÍTICO & $\begin{array}{l}\text {-Interior } \\
\text {-SEGPRES } \\
\text {-SEGEGOB } \\
\end{array}$ & 91 & 3 \\
\hline $\begin{array}{l}\text { RELACIONES EXTE- } \\
\text { RIORES, DEFENSA Y } \\
\text { JUSTICIA }\end{array}$ & $\begin{array}{l}\text {-Relaciones Exteriores } \\
\text {-Defensa } \\
\text {-Justicia }\end{array}$ & 16 & 4 \\
\hline $\begin{array}{l}\text { SALUD EDUCACIÓN, } \\
\text { SOCIAL, JUSTICIA Y } \\
\text { DEPORTE }\end{array}$ & $\begin{array}{l}\text {-Salud } \\
\text {-Desarrollo Social } \\
\text {-Educación } \\
\text {-Trabajo y Previsión Social. } \\
\text {-Deporte }\end{array}$ & 38 & 5 \\
\hline & & 32 & 6 \\
\hline $\begin{array}{l}\text { AMBIENTE, ENERGÍA, } \\
\text { TRANSPORTE Y TELE- } \\
\text { COMUNICACIONES }\end{array}$ & $\begin{array}{l}\text {-Medio Ambiente } \\
\text {-Energía } \\
\text {-Transporte y Telecomunicaciones }\end{array}$ & 10 & 7 \\
\hline PRODUCTIVOS & $\begin{array}{l}\text {-Agricultura } \\
\text {-Minería }\end{array}$ & 9 & \\
\hline
\end{tabular}

Tabla 2: Listado de instituciones donde se realizaron las entrevistas

\begin{tabular}{|c|c|c|c|c|}
\hline $\mathbf{N}^{\circ}$ & CARGO & NOMBRE & SERVICIO PÚBLICO & DEPENDENCIA \\
\hline 1 & $\begin{array}{l}\text { Director Nacional del Ser- } \\
\text { vicio Civil }\end{array}$ & Rodrigo Egaña B. & $\begin{array}{l}\text { Dirección Nacional del } \\
\text { Servicio Civil }\end{array}$ & $\begin{array}{l}\text { Dirección Nacional del } \\
\text { Servicio Civil }\end{array}$ \\
\hline 2 & $\begin{array}{l}\text { Sub Director Desarrollo de } \\
\text { las Personas DNSC }\end{array}$ & Pedro Guerra L. & $\begin{array}{l}\text { Dirección Nacional del } \\
\text { Servicio Civil }\end{array}$ & $\begin{array}{l}\text { Sub Dirección de Desarro- } \\
\text { llo de las Personas }\end{array}$ \\
\hline 3 & $\begin{array}{l}\text { Jefe de Desarrollo de las } \\
\text { Personas DNSC }\end{array}$ & Carolina Aguilera L. & $\begin{array}{l}\text { Dirección Nacional del } \\
\text { Servicio Civil }\end{array}$ & $\begin{array}{l}\text { Sub Dirección de Desarro- } \\
\text { llo de las Personas }\end{array}$ \\
\hline 4 & $\begin{array}{l}\text { Jefe Departamento Desa- } \\
\text { rrollo Organizacional }\end{array}$ & Óscar Romero A. & $\begin{array}{l}\text { Ministerio de Relaciones } \\
\text { Exteriores }\end{array}$ & $\begin{array}{l}\text { Subsecretaría de Relacio- } \\
\text { nes Exteriores }\end{array}$ \\
\hline 5 & $\begin{array}{l}\text { Encargada de División } \\
\text { Gestión y Desarrollo de } \\
\text { Personas }\end{array}$ & Norma Fernández S. & $\begin{array}{l}\text { Ministerio de Economía, } \\
\text { Fomento y Turismo }\end{array}$ & $\begin{array}{l}\text { Subsecretaría de Eco- } \\
\text { nomía y Empresas de } \\
\text { Menor Tamaño }\end{array}$ \\
\hline 6 & $\begin{array}{l}\text { Analista Departamento } \\
\text { Gestión de Personas }\end{array}$ & Óscar Villagra & Ministerio de Agricultura & $\begin{array}{l}\text { Subsecretaría de Agricul- } \\
\text { tura }\end{array}$ \\
\hline 7 & $\begin{array}{l}\text { Encargada Nacional de } \\
\text { Buenas Prácticas Labora- } \\
\text { les. }\end{array}$ & Andrea Ampuero B. & Ministerio de Salud & $\begin{array}{l}\text { Subsecretaría de Salud } \\
\text { Pública }\end{array}$ \\
\hline 8 & $\begin{array}{l}\text { Jefe Departamento de } \\
\text { Gestión de Personas }\end{array}$ & Rodolfo Cuevas P. & $\begin{array}{l}\text { Ministerio de Vivienda y } \\
\text { Urbanismo }\end{array}$ & $\begin{array}{l}\text { Subsecretaría de Vivienda } \\
\text { y Urbanismo }\end{array}$ \\
\hline 9 & $\begin{array}{l}\text { Encargado de Unidad de } \\
\text { Gestión de Personas }\end{array}$ & Camila Parra N. & Ministerio de Hacienda & Subsecretaría de Hacienda \\
\hline
\end{tabular}


entender el Servicio Civil como el sistema de empleo propio de una parte de los empleados públicos: aquellos que desempeñan funciones conectadas con el ejercicio de potestades públicas, a diferencia de otros cuyas funciones no les exigen tal singularidad. De acuerdo plantea Longo (2001), el concepto de Servicio Civil debe extenderse a la totalidad del empleo público, pero no toda clase de empleo público es Servicio Civil, sino sólo cuando éste se da en determinados contextos institucionales: aquellos que hacen posible la existencia y protección de una administración profesional. Se plantea por tanto una noción de Servicio Civil como el "sistema de articulación del empleo público mediante el que determinados países garantizan, con enfoques, sistemas e instrumentos diversos, ciertos elementos básicos para la existencia de administraciones públicas profesionales" (Longo, 2001: 6). Por lo que un sistema de Servicio Civil puede ser definido como un conjunto de reglas, jurídicas e instrumentales relativas al modo y condiciones en que el estado asegura la disponibilidad de personal con las aptitudes y actitudes requeridas para el desempeño eficiente de actividades encuadradas en el cumplimiento de su rol frente a la sociedad. Ese modo y condiciones a los que se refieren las mencionadas reglas, incluyen garantizar a la ciudadanía la profesionalidad y objetividad de los funcionarios públicos (Oszlak, 2002).

\section{Gestión de Recursos Humanos: Defi- niciones, Subsistemas y Marco de Re- ferencia}

En este apartado, se aborda la definición de dos modelos que sirvieron de referencia para orientar el análisis en gestión de personas en el sector público y la asesoría brindada por la DNSC, analizando cuáles son las tendencias actuales en gestión de recursos humanos con el objeto de definir algunos criterios sobre cómo funciona un modelo de recursos humanos en cualquier organización pública o privada, pero sobre todo, en una organización pública dado el alcance del estudio de caso. Para ello, se revisó el marco de referencia de la metodología de evaluación de sistemas de función pública o servicio civil (Longo, 2004) que ha sido desarrollada por el Banco Interamericano de Desarrollo, generando por tanto un marco conceptual que permite establecer criterios para realizar análisis comparados sobre la base de criterios comunes en sistemas de función pública en diversos países. Luego, se revisará el Modelo de Ciclos Temporales (MCT), planteado por la DNSC en un trabajo en conjunto desarrollado en 2013 con la Universidad Alberto Hurtado. Para ambos modelos, se debe tener en consideración que las prácticas de gestión de recursos humanos se enfrentan constantemente a la tensión en las organizaciones públicas. Al considerar también la evolución de la noción tradicional del empleo en las economías y sociedades desarrolladas, con transformaciones vinculadas a la producción de servicios avanzados que adquieren mayor prominencia, las tendencias de evolución orientadas principalmente al mérito y la flexibilidad no pueden pasar desapercibidas en el sector público, donde se va produciendo un análisis crítico de las disfunciones que generan sus sistemas de empleo (Oszlak, 2002; Echebarría, 2005; Gratton, 2001).

El modelo de gestión de recursos humanos elaborado por Longo (2004), releva la importancia de la planificación estratégica y la gestión de recursos humanos. Para este autor lo que hace buena la gestión de recursos humanos en cualquier organización pública o privada es que, efectivamente, se configure como un sistema capaz de contribuir eficazmente al logro de los resultados que la organización persigue, ya que en la propia formulación estratégica debe estar presente la visión de los recursos humanos, plantea que cuando una organización se propone hacer cosas, en definitiva, va a acabar pudiendo hacer en gran medida aquello que su capital humano le permite hacer (Longo, 2005). Al poner el foco en el campo de la gestión pública, se debe considerar que nuevas variables confieren al objeto de estudio una relevante complejidad. De acuerdo a hipótesis planteada por Oszlak (2009) existe un conjunto de razones técnicas, políticas, culturales y clientelares, con diferente peso en cada caso nacional que, en cierta medida, tienden a generar fuertes incompatibilidades en la organización y en el funcionamiento del Servicio Civil y, por lo tanto, profundos impactos sobre la Gestión Pública. En esta misma línea de análisis, la gestión de recursos humanos (Sekiou, 2001 citado en Gratton, 2001) se puede definir como el conjunto de medidas y de actividades que implican a los recursos humanos, que se orientan hacia una óptima eficacia y desempeño por parte de los individuos y de la organización, siendo las personas un recurso más que un costo, en función de administrar personas como forma de coordinar los recursos. En este sentido, atraer, conservar, desarrollar, motivar y satisfacer a las personas, son objetivos de la gestión de recursos humanos, así como garantizar la eficacia de la organización y sus trabajadores.

El Modelo de Ciclos Temporales (MCT) relativo a la gestión de personas, propuesto por la DNSC en un trabajo en conjunto desarrollado en el 2013 con la Universidad Alberto Hurtado, considera la repetición permanente de ciclos, donde todos los elementos ocurren de forma simultánea. Este modelo refleja el equilibrio entre las actividades relativas a ciclos de corto y de largo plazo de los cuales 
debe preocuparse la Gestión de Recurso Humano (Dirección Nacional del Servicio Civil, 2015). La articulación de la visión; la investigación de la capacidad actual y futura; la conciencia de la brecha que separa las necesidades futuras y actuales; así como la creación de una estrategia de desarrollo de personas, son todos elementos que se reajustan continuamente según los cambios en los objetivos organizacionales, agrupados en ciclos de corto, mediano y largo plazo (Gratton, 2001 citado en Gratton, 2001).

Para ambos modelos, se debe tener en consideración que las prácticas de gestión de recursos humanos se enfrentan constantemente a la tensión en las organizaciones públicas. De acuerdo a lo anterior, es que se hace necesario construir referentes específicos para la gestión de recursos humanos en las organizaciones públicas, que den pistas pertinentes para enfocar los procesos de modernización y ofrezcan herramientas puntuales para su desarrollo equitativo y sostenido en el tiempo (Oszlak, 2002; Echebarría, 2005; Gratton, 2001).

Considerando los elementos centrales que se han descrito en esta sección, a fin de desarrollar un marco conceptual que fuese de utilidad para comprender la noción de Servicio Civil y sistema de recursos humanos, es que en el capítulo a continuación se revisan los principales aspectos de la asesoría en gestión de personas efectuada por la DNSC, teniendo los elementos descritos como lineamientos rectores del análisis de la gestión efectuada por dicha repartición pública.

\section{Percepción de los Servicios Públicos y Asesoría en Gestión de Personas de la Dirección Na- cional del Servicio Civil}

\section{Aspectos generales de la asesoría en gestión de Personas desde la mirada de la Dirección Nacional del Servicio Civil (DNSC)}

Tal como plantea Longo (2001), los modelos de Servicio Civil presentes en cada país con sus características particulares, sólo expresan la existencia de diversos modelos con definiciones que van desde su sentido más amplio a su sentido más restringido, o bien relaciones laborales y de empleo que caracterizarán la uniformidad o diversidad de las regulaciones, estructuras y políticas de gestión pública del empleo y los recursos humanos en un determina- do país. Así lo reconoce también el actual Director de la DNSC, Rodrigo Egaña ..." en Chile yo diría que el modelo tiene mucha preponderancia el mérito en la selección y en el reclutamiento...pero en la nominación y en la desvinculación tiene mucha mayor preponderancia la confianza. O sea, no es que el mérito tenga preponderancia en la desvinculación, no, en Chile no tiene ninguna. Y tampoco es que el elemento de confianza tenga preponderancia en la selección, tampoco, no tiene ninguna... es una combinación de elementos que creo que hace que el modelo chileno sea bien particular. Ahora, con todo, es un modelo primero, único en América Latina, no hay otro similar y en el mundo es un modelo bastante observado por la OECD.

Ahora bien, en lo que se refiere a la asesoría en gestión de personas desde la mirada de la DNSC, se debe tener en consideración que las prácticas de gestión de recursos humanos se enfrentan constantemente a la tensión en las organizaciones públicas de orientarse a criterios normativos externos (Echebarría, 2005) o bien, que no responden precisamente a la realidad de los sistemas de recursos humanos de los servicios públicos. Al caso nacional y, tal como lo reconoce el actual Director de la DNSC, se agrega la carencia que actualmente tiene el organismo para abordar aspectos en materia de Desarrollo de Personas "...el Servicio Civil tiene funciones muy limitadas, tiene atribuciones muy limitadas y prácticamente lo que puede hacer son tareas de asesoría. No tiene tareas de rectoría en la materia y por lo tanto, lo que se ha hecho en función de políticas de desarrollo de personas es bastante parcial, ¿ya?, no es muy amplio y normalmente ha actuado en función de encargos más que por propia iniciativa porque no tiene gran posibilidad legal de iniciativa ...yo creo que ha sido mucho más exitoso en la instalación del sistema de la alta dirección pública, eso está claro y el sistema funciona, está establecido, tiene un montón de situaciones beneficiosas... lo más dificultoso ha sido que el Servicio Civil asuma una labor de rectoría en materias de políticas de desarrollo de personas".

A esto se suma, la heterogeneidad de sistemas o modelos de recursos humanos presentes en Ministerios y sus respectivas Subsecretarías. En este mismo sentido el Sub Director de Desarrollo de Personas de la DNSC, Pedro Guerra, reflexiona... "Hay servicios que todavía están en el paleolítico en materia de gestión de personas. Hay servicios, que desde el punto de vista de la estructura, todavía mantienen sus áreas de RRHH debajo de un área, por ejemplo, de administración de finanzas. Hay servicios que todavía le llaman RRHH, otros le llaman personal, otros, gestión de personas. Por tanto, el principal problema que tenemos nosotros y es parte de la pega que estamos haciendo, es que no tene- 
mos un mínimo común en gestión de personas que tú digas: "mira, todos los servicios públicos tienen determinados procedimientos, tienen un reglamento especial de calificaciones, están funcionando los cursos de formación...", eso hoy día no está. Entonces, el mínimo común hoy día no existe. Hay servicios que están muy desarrollados como te dije y otros que no.

A través de las entrevistas que se efectuaron, se evidenció la heterogeneidad de realidades de los sistemas de recursos humanos en los Ministerios seleccionados. Lo que se condice también con los resultados obtenidos en el informe de la DNSC titulado "Barómetro de la Gestión de las Personas en el Estado" (2013) y que contiene los resultados generales de la primera aplicación a Servicios Públicos. Tal como recuerda la Jefa de Desarrollo de Personas de la Subdirección, Carolina Aguilera, ... la evaluación que teníamos en esos años, sabes que la mayoría de las áreas de gestión de personas eran, más bien, áreas de personal, vinculadas a temas administrativos, a temas de administración de permisos, vacaciones, remuneraciones, en esa línea incluso algunos sin remuneraciones. Entonces, más bien, para nosotros tenía otro objetivo que no era solo medir cuanto se había instalado sino que formar a estas jefaturas que entendíamos, tenían características bien disímiles y lo segundo era instalar este modelo que era como... desde aquí vamos a empezar a conversar y vamos a estar todos como en esta misma línea. Bajo este diagnóstico entonces, la SDDP desarrolló transferencia de conocimiento hacia los SPAC a través de capacitaciones efectuadas en alianza con la Universidad Alberto Hurtado. El objetivo de estas capacitaciones, fue dotar de herramientas a las jefaturas de recursos humanos de los SPAC y también instalar el Modelo de Ciclos Temporales como una herramienta de gestión de personas. Lo anteriormente expuesto constituye una contextualización preliminar de la percepción de la Alta Directiva de la DNSC respecto del tema del estudio de caso. En efecto, la percepción de la Alta Directiva de la DNSC respecto a las cinco temáticas que fueron consideradas para el análisis de contenido. De acuerdo a las subcategorías (favorable, desfavorable y neutra) consideró los desafíos y características de la DNSC en temas relacionados con la gestión y desarrollo de políticas de personas, los cuales fueron revisados y sintetizados en detalle en los capítulos anteriores. Las estadísticas obtenidas se complementaron con abstractos correspondientes al registro de las entrevistas, lo que permitió realizar un análisis más acabado de las cifras obtenidas.

Acerca de la temática referida al desarrollo de nuevas capacidades en la gestión de personas, se analizaron todas aquellas apreciaciones que tenían relación con la generación de capacidades técnicas en los equipos de trabajo, como también se observó aquellos aspectos referidos a la gestión interna desarrollado por la DNSC, sus debilidades y fortalezas y cómo éstas afectaban o no el desarrollo de nuevas capacidades en la gestión de personas en los SPAC. En esta temática la valoración se inclina por una estimación favorable respecto de las acciones efectuadas referidas al desarrollo e instalación de nuevas capacidades en los Servicios Públicos, alcanzando un $28 \%$. Sin embargo, cabe precisar que un $57 \%$ se refiere a valoraciones desfavorables o neutras. Lo anterior apunta principalmente al reconocimiento por parte de la DNSC de la heterogeneidad de realidades en sistemas de recursos humanos en los Servicios de la Administración Central junto con la desorganización con la que se ha llevado la instalación de capacidades en los servicios asesorados. Tal como reconoce el Director de la DNSC... yo creo que el servicio ha tenido... ha hecho cosas interesantes pero son mucho más desorganizadas, hay temas sobre convenios de desempeño, sobre formación, sobre buenas prácticas laborales, sobre climas organizacionales, sobre políticas de personal, sobre rediseños organizacionales. Hay un conjunto de materias que son temas transversales en políticas de desarrollo de personas que se han aplicado para servicios específicos y eso no ha sido, ni horizontalmente masivo para toda la administración, ni con la misma intensidad respecto de cada quien, sino que eso depende de los acuerdos que se logren con cada servicio...De lo anterior, fue posible inferir que existe un reconocimiento de ejecución de iniciativas, más la ausencia de directrices o lineamientos normativos, impide que existan avances sustantivos en mejoras de la carrera funcionaria.

En este sentido, el Sub Director de Desarrollo de Personas de la DNSC reflexiona sobre una iniciativa particular que ejemplifica como la instalación de mejoras se encuentra sujeta a factores exógenos a la propia DNSC e inclusive a los mismos jefes de servicio ...El 2006 aparece el código de buenas prácticas laborales, eso que parece una cuestión declarativa, significó o debiera haber significado un montón de procesos importantes en políticas de gestión de personas, a 9 años de implementado eso hay distintas evaluaciones, de hecho, lo que estamos haciendo con los gremios, la ANEF, etc., una de las principales tiene que ver con que se declaró mucho pero se hizo poco. Entre medio hubo cambio de Gobierno, en el Gobierno anterior, no es que haya desincentivado pero no impulsó con mucha fuerza el seguimiento a este apoyo. Pero también tuvimos nosotros problemas que estamos resolviendo. Entonces, en este año hemos enviado el instructivo presidencial y lo que pretende es instalar prácticas y políticas de personas de aquí hasta el 2018, resolviendo todos estos 
temas que te mencionaba. Un nivel de base mínima, el entendimiento común, entonces, está la idea de estandarizar, está la idea de recoger buenas prácticas y poder relevarlas y principalmente tener una mirada sectorial también de implementación, ya no ese servicio uno a uno por eso nosotros nos hemos reformulado.

Si bien la práctica administrativa de la DNSC incluye una mirada interna, se evidenció que la gestión efectuada durante estos años se enfoca a un acompañamiento de los jefes de recursos humanos y analistas. En la actualidad cobra cada vez mayor preponderancia el rol que la DNSC ha desarrollado con las asociaciones de empleados fiscales a objeto de estar presente en los conflictos internos de las instituciones en materias de carrera funcionaria. De acuerdo a lo anterior y, no obstante se han realizado esfuerzos importantes, se constató que en el período no se ha generado una base en común de avance en ésta materia en los SPAC. Concluyendo por tanto que el $57 \%$ respecto de las valoraciones desfavorables o neutras, tienen su fundamento en el consenso por parte de la DNSC de que la gestión en función de la demanda del entorno ha generado avances, pero en distintos niveles, no siendo factible establecer avances en común ni en los mismos ámbitos en recursos humanos. La DNSC tuvo una visión crítica al respecto evaluando el actual rol que poseen, en donde se evidenció la necesidad de contar con un rol rector en materia de gestión de desarrollo de personas contenido en una modificación legal, con el objeto de dotarlos de mayores atribuciones.

A continuación se analizan los resultados obtenidos respecto de la influencia de la estructura orgánica, las costumbres y creencias de la organización y, la puesta en marcha de buenas prácticas laborales. Acerca de la temática referida, se analizaron aquellos aspectos relacionados con la gestión interna desarrollado por la DNSC, sus debilidades y fortalezas y cómo éstas impactan o no en la consolidación de buenas prácticas laborales. De acuerdo a los datos obtenidos, se observó que la gestión de las relaciones humanas y sociales junto con la estructura organizacional en el ámbito de las relaciones se pondera de manera desfavorable, alcanzando un $53 \%$. Dicha tendencia se inclina por el desafío que implica establecer entre la organización y sus colaboradores atraer, conservar, desarrollar, motivar y satisfacer a las personas, garantizando la eficacia de la organización y sus funcionarios. Por otro lado, se identificó como la estructura organizacional influye en la instalación de buenas prácticas laborales. En esta línea de análisis el Director de la DNSC, señala ... Todo proceso de cambio en una organización afecta lo que hacen las personas y nosotros nos hemos dado cuenta que hasta ahora el Servicio Civil estaba muy concentrado en las relaciones con los directivos, ehh, funcionales de los servicios públicos pero no teníamos una relación con los gremios.

En consecuencia, cuando estas relaciones toman una acción de grupos o bien colectiva y, a esto se suman actitudes divergentes u opositoras, las políticas y prácticas de personas cobran un rol central, para realizar un direccionamiento del grupo humano y así, alinearlos con la consecución de objetivos de la organización, orientados hacia una óptima eficacia y desempeño por parte de los individuos. La gestión de las relaciones humanas y sociales por tanto, pasa a conformar un elemento estratégico dentro de la organización, siendo un elemento central la capacidad técnica y profesional, pero también y, en igual medida, la motivación individual y el bienestar organizacional. Así lo visualizó el Sub Director DDP DNSC, quien señaló ...durante todos los tiempos que por años hemos dicho "no, es que la gente que trabaja en el Estado tiene un sello especial, tiene una vocación, tiene servicio público", me encanta, yo lo vivo, lo siento exactamente pero nos quedamos cortos porque esta cuestión no es el Hogar de Cristo, no necesitamos gente que venga a hacer apostolados, necesitamos también, gente que se crea con las capacidades profesionales tanto o mejor que en las empresas privadas. Y esa es una mirada a futuro... ni tan a futuro porque ya está ocurriendo y estamos quedando afuera. Lo anterior, implica por tanto el desarrollo de una gestión estratégica con especial referencia en la gestión enfocada en el ciclo de vida de las personas en una organización. En este sentido, la Jefa de Desarrollo de Personas de la SubDirección reconoce... en Desarrollo Organizacional más que meternos en temas vinculados necesariamente a reestructuración o a diseños organizacionales, hemos estado más enfocados en temas vinculados a ambientes laborales y a conciliación y calidad de vida. Yo te diría que... entonces también desde el modelo hemos priorizado algunos de los temas para trabajar. En esta misma línea de trabajo el Servicio Civil puso a disposición el documento "Conciliación de la vida personal y familiar con el trabajo en la Administración Central del Estado: Propuesta para su gestión", el cual tuvo por objetivo principal proporcionar nociones teóricas y prácticas del tema. En el año 2012 el Servicio Civil elaboró en conjunto con la Superintendencia de Seguridad Social (SUSESO), el documento "Propuesta de Estrategia para la Medición e Intervención de las Condiciones Laborales en los Servicios Públicos", con la finalidad proponer una metodología (ISTAS 21) para la medición, prevención e intervención sobre los riesgos psicosociales en el trabajo. Junto con ello, elaboró también orientaciones para la gestión del clima laboral y, en el mismo año, publica los resultados de la Encuesta de Acoso Laboral y Sexual 2012 y, al año siguiente la 
Encuesta de Acoso Laboral y Sexual 2013, la que se aplicó a los servicios públicos de la administración central del Estado.

Sin embargo, durante la implementación de dichos programas, repercuten realidades que conviven con la lógica de desarrollo de buenas prácticas laborales. Durante la realización de las entrevistas, fue posible inferir que la actual jurisprudencia normativa con la que es regulada la carrera funcionaria, traba si es que no entorpece en algunos aspectos la implementación efectiva de las políticas y prácticas de personas que son promovidas por la DNSC. Por consiguiente, es posible determinar que en esta temática, existe un conjunto de aspectos técnicos, políticos, normativos y culturales que tiende a generar incompatibilidades en la organización y en el funcionamiento del Servicio Civil y, por lo tanto, profundos impactos de carácter negativo sobre la implementación de políticas y prácticas de personas. De ahí que, el Sub Director DDP indicó... eso te va generando vacíos en la administración que después te va generando problemas de clima porque como no puedes cubrir las plantas de los grados más bajos, empiezas a contratar por contrata y al contratar por contrata, contratas a lo mejor una función a alguien que si corresponde a su remuneración pero que el de al lado, que está de planta por tantos años tiene una remuneración menor a ella y se generan problemas de clima, esos problemas redundan en las relaciones laborales, en los gremios, entonces, es súper complicado atreverse a innovar o a modernizar cuando en verdad tienes un montón de trabas legales, yo creo que ese es un problema complejo también de nuestra parte pero también me parece que era una excusa y que es el tercer problema que yo te definiría, que tiene que ver con el "low" perfil de nuestros jefes de personas y recursos humanos. Yo creo que durante muchos años hemos sido complacientes en entender que la problemática es tan grande que mejor no hagamos nada. Es por ello, que la definición e implementación de buenas prácticas laborales y el emprendimiento de acciones orientadas al desarrollo de cambio organizacional y cultural en la ACE, se ha efectuado entonces de manera gradual en cada servicio y su éxito o fracaso, radica en el sentido estratégico entregado por los diferentes actores involucrados. Hasta cierto punto, y como fue posible inferir de las entrevistas, existe también en el ordenamiento interno de la DNSC aspectos que tiene directamente relación con los objetivos alcanzados y que tienen que ver principalmente con aspectos referidos a la gestión que realizan a nivel de autoridades de servicio.

Por otro lado, las apreciaciones favorables alcanzan un $43 \%$ en esta temática, fundamentándose principalmente en aquellas apreciaciones que apun- tan a las condiciones favorables que propician el desarrollo de prácticas laborales positivas. En específico, se relevó la importancia en el compromiso de las jefaturas de recursos humanos, como también el compromiso de las autoridades de los servicios. Que si bien permitió generar e incentivar prácticas, concluyeron que aquellos avances carecían de una socialización adecuada a los funcionarios o bien, una continuidad en el tiempo.

A continuación, se presenta la percepción de la Alta Directiva de la DNSC respecto a la temática referida a cambios en la gestión de personas y existencia o no de nuevas prácticas institucionales. Acerca de la temática referida, se analizaron aquellos aspectos relacionados con el efecto de la asesoría del Servicio Civil y la percepción de los entrevistados referente a instalación de políticas en gestión de personas, ejecución y práctica en el tiempo de éstas. Junto con ello, también se observó la generación o no de nuevos procesos institucionales asociado a los ciclos de vida laboral.

Considerando las estadísticas, se obtuvo que un $60 \%$ corresponde a valoraciones favorables por lo que es importante recordar, que en 2013 se comenzaron a implementar los Convenios de Asesoría en Gestión de Personas (CAGP) como una nueva estrategia para el desarrollo de las personas en el Estado, orientada a instalar capacidades de gestión brindando asesoría para consolidar el Modelo de Ciclos Temporales (MCT) relativo a la gestión de personas, propuesto por la DNSC en un trabajo en conjunto desarrollado con la Universidad Alberto Hurtado. Dichos convenios tenían como objetivo sensibilizar a las autoridades y a los jefes intermedios de los servicios públicos de que la gestión de personas debe relevar la importancia de la planificación estratégica y la gestión de recursos humanos, ya que cuando una organización se propone hacer cosas, en definitiva, va a acabar haciendo en gran medida aquello que su capital humano le permite hacer. Sobre este punto, un miembro del equipo de la Subdirección durante este período reflexionó ...tiene que ver con la voluntad y por eso para nosotros es súper clave que el jefe de servicio sea quien esté a cargo o entienda que es responsabilidad de la gestión de personas y por tanto lo endose a los jefes de cada área o de cada línea porque la gestión de personas es un tema que es bien importante. El sensibilizar a las autoridades y a los jefes intermedios respecto de que la gestión de personas no es de la gestión de personas sino que es una responsabilidad en línea y que es parte de la gestión propia y directiva es súper difícil y yo creo que ahí se juega bastante de lo que pase en la gestión de personas porque si tú tienes los procesos establecidos pero los jefes, fundamentalmente los jefes intermedios que es el cuadro más amplio de esta estructura en el servi- 
cio, no lo aplican, no lo conocen o no lo validan, no tiene ningún sentido tu tengas declarada las políticas.

En este sentido, el Modelo de Ciclos Temporales propuesto por la DNSC se encontró con un sistema de carrera que en la práctica, durante las últimas dos décadas ha prevalecido en el sector público. Dicho sistema de personal combina un sistema de carrera junto con un sistema de empleo. A esto se suma, la heterogeneidad de los servicios públi$\cos \mathrm{y}$, que la forma en la que se ha desarrollado la gestión de personas en temas que muchas veces exceden el campo normativo, ha permitido la consolidación de prácticas que combinan tanto elementos de un sistema de carrera como un sistema de empleo. Agregando a lo anterior, la implementación de prácticas de gestión más actuales. Ahora bien, en este ámbito y tal como lo indicó el Director de la DNSC ... nosotros en ese sentido somos asesores de...por aquí dice: la función de colaborar con los servicios públicos, claro nosotros colaboramos en tanto y en cuanto un servicio público tenga interés en recibir nuestra colaboración, sino tiene eso nosotros podemos incentivarlos e impulsarlos, etc. No podemos realizar un trabajo con ellos, en el fondo nosotros no tenemos la labor de rectoría y hasta que no tengamos la labor de rectoría en materia de desarrollo de políticas de personas va a ser muy difícil que tengamos una acción más fuerte, más potente. El elemento indicado, es un factor a considerar, dado que si bien los servicios públicos asesorados poseen políticas en gestión de personas que consideran todos los elementos necesarios, se constató que en la práctica muchas de éstas no son aplicadas, ya sea porque no se difundieron o porque nunca los funcionarios sintieron que ese documento era parte de la organización o que los reflejaba. Siendo este un elemento que perjudica la implementación de buenas prácticas laborales. Lo anterior explica en cierto sentido aquellas valoraciones desfavorables y neutras que concentraron un $40 \%$ para ésta temática. Se planteó también la existencia de SPAC que han experimentado pequeños avances en gestión de personas y nuevas prácticas institucionales., pero con un alto grado de consistencia respecto de éstos y por tanto, tienen un mayor nivel de instalación en la organización y legitimidad. Por otro lado, se encuentran aquellos servicios públicos que han planteado cambios sustantivos, pero con poca consistencia en las acciones, siendo avances más bien declarativos que de fondo.

Cabe precisar que la labor de la DNSC en este escenario se enfoca en apoyar esta implementación y fortalecer la relación con sus usuarios a través de la labor de asesoría, pero teniendo en consideración que este rol de asesoría es una cuestión que considera dos aspectos que se deben tener a la vista: por un lado, la asesoría es "a demanda" o "a pedido", es decir si la Institución (analista o jefe de gestión de personas de un SPAC determinado) solicita asesoría, se va asesorar, si no se solicita dicha asesoría no lo asesorarán. El otro aspecto a considerar, es que queda restringido a un grupo de expertos, los que entran a la organización, ven un tema determinado, asesoran y luego salen, lo que no genera una continuidad de implementación de mejoras e impide lograr estándares entre diversos servicios públicos asesorados. Una alternativa de mejora en este punto es el Instructivo Presidencial sobre Buenas Prácticas Laborales en Desarrollo de Personas en el Estado dictado en enero del 2015. Dicho documento consideró dentro de sus principios orientadores la revalorización de la función pública y la generación de nuevas prácticas en gestión de personas. Para comprender la importancia de dicha iniciativa, el Sub Director DDP DNSC en su entrevista puntualizó...Sacamos un instructivo que fue súper potente, lo firmó la Presidenta...y resulta que la cantidad de contenidos que tiene eso significa que cada servicio lo puede leer y pueda aplicar a su arbitrio y lo pueda entender. Y nos pasamos unos buenos meses operacionalizando dentro de la implementación de este instructivo con acciones súper concretas que les estamos pidiendo a los servicios, con plazos súper concretos en cada una de las acciones y con medios de verificación específicos. Además de una metodología de seguimiento y reporte, les estamos pidiendo plazos para estos reportes y lo pide la presidenta en este instructivo, reportar una vez al año el avance de esas materias y por tanto hay una guía súper clara de que todos los servicios sepan que es lo que tienen que hacer y cuando lo tienen que hacer.

De acuerdo a este nuevo escenario, se constató que se ha generado un nuevo modelo de gestión en la propia DNSC, sin embargo, concluyeron que un elemento central para obtener avances sustantivos en estas materias es la voluntad, siendo clave que el jefe de servicio sea quien esté a cargo o entienda que también es responsable de la gestión de personas y por tanto lo endose a los jefes de cada área o de cada línea. Otro punto a considerar es la legitimidad que se logre alcanzar con dicho instructivo y sus contenidos en los propios funcionarios, la credibilidad de que el instructivo efectivamente orientará la gestión de personas bajo la lógica de personas, es un tema que es clave, por lo que un desafío en este ámbito ha sido la sensibilización de las autoridades y jefes intermedios respecto de que la gestión de personas debe ser concebida como la piedra angular de la planificación estratégica de una organización y, por tanto, tiene que encontrarse consensuada por los distintos actores que intervienen en la implementación de dichas políticas y prácticas de gestión de personas. En suma, los cambios en la gestión de 
personas y existencia o no de nuevas prácticas institucionales debe estar fundamentada en la premisa de que un grado alto de legitimidad de los cambios a implementar permitirá una instalación y desarrollo sostenido en el tiempo de las políticas y prácticas, lo descrito solo se logra cuando el objetivo traspasa la formalidad del documento físico, sino que se traslape a la gestión estratégica de la organización.

A continuación, se presenta la percepción de la Alta Directiva de la DNSC respecto a la temática referida al impacto de los ciclos políticos en la implementación de buenas prácticas laborales. Acerca de la temática indicada, se analizaron aquellos aspectos relacionado con el impacto de la esfera del mundo político en la administración pública. A su vez, se observó la implicancia o no de factores que surgen producto de la interacción de ambas esferas en la implementación de buenas prácticas laborales.

Para realizar el análisis de esta esfera, se consideró el modelo operativo con el cual el Servicio Civil ha funcionado desde su creación. De acuerdo a ello, se evidenció que la gestión efectuada durante el período, no consideró una separación de la esfera política de la administrativa. En este sentido, la evidencia empírica comprobó que el espíritu del funcionamiento del Servicio Civil, resguarda la gestión de la administración pública de la esfera del mundo político, más no excluye ni enajena un componente del otro. El marco de acción por tanto del Servicio Civil en este sentido ha considerado la existencia y convivencia de ambas esferas. Por ello, es relevante observar los resultados obtenidos, ya que existe una clara paridad entre las valoraciones por parte del Servicio Civil (31\% desfavorable, $31 \%$ favorable y $38 \%$ neutro), referente a como influyen los ciclos políticos en la instalación o no de nuevas prácticas laborales. Lo anterior, permitió dar cuenta de que si bien consideran la influencia de los ciclos políticos, no la trasponen como el motivo único y fundamental, en la lógica de que la alternancia política es el factor que determina el poco avance, por ejemplo, que se han tenido en estas materias.

Se podría considerar que la discusión entre política y administración es la piedra angular para definir continuidad de mejoras y lineamientos, no obstante, el reconocimiento y convivencia de ambos factores permite reconocer también el supuesto de que dicha convivencia supone que los funcionarios no son neutrales y deberían estar comprometidos con la buena administración. En esta línea de análisis resulta conveniente reconocer que las organizaciones públicamente administradas funcionan en un medio político, social y económico, por lo que asegurar la estabilidad de las políticas en gestión de personas es uno de los más grandes desafíos. Así lo planteó el Director de la DNSC en su reflexión sobre este punto... yo diría que las políticas de desarrollo de personas la estabilidad debiera ser bastante mayor porque son los equipos permanentes de la administración que no deberían de cambiar, pudieran cambiar sobre los objetivos que pueden alcanzarse en cada área pero la gente debería estar en condiciones de poder colaborar para la consecución de distintos objetivos de política pública. Donde hay más impacto, en el sistema de alta dirección pública y ahí creemos que hay que hacer una reingenieria importante para proteger el sistema. No obstante lo planteado por la autoridad, es pertienente también tener en consideración la práctica clientelar que puede generarse al momento de gestionar la carrera funcionaria al interior de los servicios públicos, siendo este también un componente de índole político al vincular la gestión de funcionarios al interior de las organizaciones públicas con relaciones de conveniencia, afectividad o compromisos ajenos a la labor puramente administrativa. No hay que olvidar que el Sistema de Alta Dirección Pública regula el ingreso de Altos Directivos, con el objeto de otorgar un equilibrio entre el mérito y la confianza en la designación. Dicha claridad alcanzada por el Sistema de Alta Dirección Pública, se evidenció que no ha sido traspasada a la gestión de personas bajo la óptica de ciclo de vida laboral, con el objeto de regular aspectos como la carrera, mérito, confianza o idoneidad. En esta análisis el Sub Director DDP planteó... tener preparada gente al interior de la institución que no tenga que ver con la sensibilidad o los cambios políticos y que tenga la misma capacidad y que tenga las mismas posibilidades de decisión como las que pueda tener un titular. Eso es por un lado, y por otro lado, lo que sí, es una parte que ha sido compleja de administrar y ahí me parece que hay un tema mayor que tiene que ver con una demanda de la ANEF sobre la estabilidad de los funcionarios al momento de los ciclos de cambios políticos. En este orden de ideas, cabe precisar la necesidad de establecer delimitaciones que permitan generar relaciones que resguarden derechos de los funcionarios públicos y también den respuesta a cambios necesarios para las organizaciones. En este apartado también se observó la necesidad de regular la relación clientelar generada por la convivencia de lo político-administrativo, en torno a evitar el fomento y consolidación de prácticas clientelares entre diversos grupos según intereses de orden particular o ideológico, siendo este un factor crítico que debe ser considerado al momento de gestionar la carrera administrativa.

A modo de resumen, las entrevistas y su respectivo análisis plantearon aspectos que influyen en distintos ámbitos en la consolidación de prácticas laborales que fomenten la gestión de personas en los servicios públicos. Sin embrago, un factor clave se 
refirió al actual rol que posee la DNSC. Como se indicó, el Servicio Civil tiene funciones y atribuciones limitadas, referidas principalmente a labores de asesoría. Si bien el Instructivo Presidencial 2015 sobre Buenas Prácticas Laborales en Desarrollo de Personas en el Estado entrega ciertas tareas de rectoría a la DNSC en la materia, éstas son atribuciones bastante parciales. Siendo por tanto, desde la perspectiva de los entrevistados, el rol de asesoría o rectoría, una definición necesaria para lograr avances sustantivos en políticas de desarrollo de personas en los SPAC.

La realización de entrevistas en profundidad que se efectuó a la Directiva de la DNSC fue de gran utilidad para reconocer factores y elementos que inciden y explican el fenómeno de estudio. Pero a objeto de complementar el enfoque de análisis, es que a continuación y con el propósito de obtener la otra mirada, es que se efectuaron las indagaciones en terreno y entrevistas en profundidad de analistas y jefaturas en áreas de desarrollo de personas y recursos humanos provenientes de los SPAC.

\section{Aspectos relacionados con la percep- ción de los Servicios Públicos y la implementación de prácticas laborales en Gestión de Personas producto de la asesoría brindada por la Dirección Nacional del Servicio Civil (DNSC)}

En esta parte del estudio, la indagación se enfocó en los jefes y analistas de gestión de personas de los SPAC que conformaron parte de la muestra del estudio de caso. Lo anterior, resultó de gran utilidad ya que permitió conocer la visión y percepción de los servicios públicos que han interactuado con la DNSC. Para ello, la estructura de las entrevistas efectuadas se enfocó en conocer en una primera parte, la realidad y características de la gestión de personas en cada repartición junto con la interacción con asociaciones de empleados y posiciones de las alta directiva respecto a temas de personal. Luego y desde esa óptica, se consultó acerca de aspectos sobre el rol, contribución, pertinencia, eficacia y calidad de la asesoría recibida por parte de la DNSC, lo que permitió generar una conversación adecuada para finalmente explayar la entrevista a temas más sensibles de abordar, los que se realizaron fuera de la grabación de audio, siendo registradas en notas de campo.

Para dar inicio a esta parte de la investigación, resulta conveniente mencionar que el desarrollo e implementación de aspectos de reforma relativos a la carrera funcionaria por parte del Servicio Civil, se basó principalmente en el aprovechamiento de con- tingencias que dieran visibilidad a la Sub Dirección de Desarrollo de las Personas. En este contexto, la estrategia adoptada, responde a factores principalmente originados del contexto e introducidos a la estructura organizacional como aprendizaje u oportunidades (Garrido, 2010). Esta modalidad abrió la puerta al aprendizaje estratégico de la DNSC en este ámbito.

En cuanto al desarrollo de nuevas capacidades en la gestión de personas, se observó una valoración favorable que alcanzó un $83 \%$. Dichas cifras se debieron principalmente a la relación existente entre capacidades desarrolladas e importancia de la acciones emprendidas por el Servicio Civil. Tal como declara uno de los analistas Andrea Ampuero Belmar- Encargada de Buenas Prácticas Laborales, Ministerio de Salud ...ellos han sido parte esencial de formarnos a nosotros, a quienes trabajamos en esta unidad, como personas que podamos implementar esto en la institución, yo me imagino que en las demás instituciones sienten eso también. Entregan gran parte del cuerpo de conocimiento. Por lo que la gestión efectuada durante estos años, enfocada principalmente a un "acompañamiento" de los jefes de recursos humanos y analistas es un aspecto valorado por parte de sus usuarios, reconociendo la entrega de conocimientos que han efectuado en estas temáticas como son los planes de capacitación efectuados junto con otras iniciativas de capacitación y encuentros anuales. En este sentido, se evidenció su impacto positivo en el desarrollo de capacidades de los encargados y analistas. En esta misma línea, se destacó la generación de capacidades y roles de mediación entre los sindicatos de empleados públicos y el Ministerio de Hacienda que en oportunidades ha tenido la DNSC, pero que sean ido consolidando durante los últimos años y que ha posicionado a la DNSC como una instancia mediadora con los gremios.

Se constató también que los planes trienales, herramienta consignada en el Instructivo Presidencial de enero del 2015, significó para los servicios en cierto sentido "ordenar lo que ya tenían", Norma Fernández Sánchez-Encargada División Gestión y Desarrollo de Personas, Ministerio de Economía, Fomento y Turismo reflexiona al respecto ...no es muy lejano, es decir, cuando uno revisa los planes ya hay muchas cosas que estaban, por lo tanto, lo que se está haciendo es como de aglutinarlas, de ir dándole una mirada o un enfoque distinto. Luego, cabe resaltar que si bien el instructivo ha tenido efectos positivos en su desarrollo e implementación, la puesta en práctica y el éxito de ésta ha tenido ciertos impactos para la gestión interna de los SPAC, dado que sus alcances y lineamientos se sobrepusieron a los convenios de asesoría que algunos servicios públicos habían firmado, lo que implicó 
cambios en los lineamientos adoptados. En síntesis, sólo se alcanzó a trabajar un par de meses el pasado año sobre la base de los convenios, algunos entrevistados indicaron que no alcanzaron a terminar todo ese trabajo ni alcanzar los objetivos que se habían planteado conseguir. Por otro lado, destacaron que la implementación y desarrollo del instructivo impactó positivamente en la gestión de los jefes de las áreas de recursos humanos, dado que lo percibieron como una herramienta que los empoderó internamente en sus organizaciones para implementar mejoras. Rodolfo Cuevas Pinto- Jefe de Departamento de Gestión de Personas, Ministerio de Vivienda y Urbanismo reflexionó al respecto... Hemos tratado en esta instancia que el instructivo no se transforme en eso, que no sea un trabajo extra para el funcionario que está en el día a día, sino que entienda que son los procesos que nosotros llevamos, instrumentalizarlos.

Dicho instructivo y su aplicación, se constató que tuvo efectos en dos sentidos: por una parte, los jefes de servicio tuvieron una oportunidad de empoderar y visibilizar los cambios en gestión de personas y, por otro, se debió realizar una adecuación de la estructura de funcionamiento de la Subdirección de Desarrollo de Personas (SDDP) en la DNSC para responder a las nuevas demandas surgidas por parte de los SPAC. Para asumir estos nuevos desafíos, es que se adecuó la estructura orgánica de la SDDP con el diseño e implementación de un nuevo modelo de gestión interna. En este punto surgió escepticismo por parte de los entrevistados, principalmente, sobre la capacidad operativa y dotación de recursos humanos del propio Servicio Civil, poniendo a prueba la capacidad de éste para atender y dar respuesta a la totalidad de unidades de recursos humanos de la ACE. No obstante, se evidenció que la labor efectuada por la DNSC durante estos años, tiene una valoración muy positiva, sobre todo su rol en la capacitación que han brindado. Dicha capacitación posibilitó el desarrollo de diversos productos en los servicio públicos, por ejemplo, la metodología para el diseño de una política de personas, información de normativa legal acerca del tratamiento del acoso sexual o laboral, entre otras temáticas, buenas prácticas en los procesos de contratación y desarrollo de personas, lo que desembocó en un ordenamiento interno en cada área de personas.

Finalmente, se constató que la implementación de capacidades ha sido efectiva por parte del Servicio Civil, se reconoció el real aporte y el gran valor agregado que tiene para los servicios públicos trabajar con su asesoría, no obstante, se indicó que dicho trabajo sería más valioso, con una figura legal que empoderará los lineamientos y directrices que se entregan desde el Servicio Civil, siendo este aspecto coincidente con lo planteado también por parte de la alta directiva de la DNSC.

A continuación, se presenta la percepción referida a la influencia de la cultura organizacional en la consolidación de buenas prácticas laborales. Acerca de la temática mencionada, se analizaron aquellos aspectos relacionados con el impacto de la estructura orgánica, las costumbres y creencias de la organización. A su vez, se analizaron aquellos aspectos relacionado con la gestión interna y se observó la implicancia o no de éstos factores en la consolidación de buenas prácticas laborales. Se obtuvo solo un $25 \%$ de valoraciones fueron favorables y un $62 \%$ de valoraciones desfavorables. Ello se explica principalmente por el enfoque que los servicios han tenido en la aplicación del Instructivo Presidencial 2015. En esta línea, Andrea Ampuero Belmar- Encargada de Buenas Prácticas Laborales, Ministerio de Salud reflexionó... pero ahora con el instructivo presidencial la idea es que se incorporen también en el diseño de los productos que solicitan vinculación con los distintos subsistemas de gestión de personas. Ahora bien, el tema interno referido a los distintos subsistemas que implica la gestión de personas y referidos a la estructura organizacional, es un tema que se tuvo en consideración en el desarrollo de la investigación, dado que la mayor parte de las Subsecretarías se encuentran desconcentradas en Secretarías Regionales Ministeriales (SEREMIS), algunas de ellas también consideran servicios descentralizados, corporaciones o agencias, por los que sus funciones responden a diversas prácticas administrativas y la estructura organizacional y cultura organizacional es distinta en cada una de ellas. En este contexto, se destacaron los siguientes aspectos como elementos comunes y que fueron fundamentales para la interpretación de las estadísticas obtenidas. En primer lugar aquellos servicios que consideran desconcentración en regiones, indicaron que sus servicios regionales esperan tener sus espacios de caracterización local, generándose por tanto demandas en función de que quieren tener sus propios lineamientos, indicando también que les faltan recursos, versus periodos en que indican que les faltan lineamientos desde el nivel central, generándose un desequilibrio entre la realidad regional y el nivel central. Otro elemento en común, fue la caracterización que se hizo frente al rol de las jefaturas de áreas de negocios, siendo un elemento común que dichas jefaturas estén enfocados sólo hacia la producción, hacia el logro de objetivos, dejando en segundo plano la gestión de personas, no teniendo un enfoque estratégico en este ámbito. De modo similar, influyen los canales de comunicación e información de las mejoras que se implementan en gestión de personas, por ejemplo, se mencionó la existencia de panfletos aludiendo incumplimiento de derechos y falta de transparencia en los pasillos luego de los 
procesos de ascenso anuales y otras prácticas internas, que tensan la relación acerca de las decisiones de recursos humanos, por ejemplo: asignación de grado a personas que están en planta versus aquellos que están en modalidad contrata. Por otro lado, indicaron que no se ha sabido comunicar por parte de la DNSC este trabajo a los funcionarios y a las asociaciones, lo que en oportunidades generó ciertas tensiones internas. Finalmente, un denominador común entre los entrevistados se enfocó en falta de presupuesto para impulsar las reformas, siendo dos temas centrales: ascensos y la realidad de funcionarios contratados en modalidad honorario y contrata junto con las labores de estudio y capacitación que considera el instructivo. Lo anterior no se condice con el presupuesto institucional, Rodolfo Cuevas Pinto- Jefe de Departamento de Gestión de Personas, Ministerio de Vivienda y Urbanismo reflexionó... Hoy día el principal problema que nos encontramos, y debe ser transversal en el sector público, es el presupuesto. Los recursos que muchas veces tú no cuentas para poder implementar de mayor forma las medidas...Entonces, el Servicio Civil tampoco te entrega esas respuestas, no se te pone del brazo a decir, ok vamos nosotros como sector público a defender el presupuesto, un incremento en alguna glosa que nos permita desarrollar de manera específica el instructivo, no. Este punto se condice con la tensión respecto de los procesos de ascenso y contratación, sin embargo, se evidenció en las entrevistas que si bien el presupuesto es un tema central al momento de avanzar en mejoras en gestión de personas, el compromiso y voluntad de las autoridades de los distintos SAC es un punto central, al momento de implementar y desarrollar buenas prácticas al interior de la organización y definir las prioridades que tendrá la ejecución presupuestaria en cada institución. La realidad particular de cada SPAC incide en la consolidación de buenas prácticas laborales, la estructura orgánica es un factor a considerar, toda vez que los vínculos contractuales entre el Estado y las personas que se desempeñan como funcionarios públicos, tienen distintos matices en cada servicio, siendo un tema base y de fondo que tensiona la estructura al momento de desarrollar políticas de desarrollo de personas, una solución en este ámbito implica presupuesto y, sobre todo, voluntad política.

En cuanto a cambios en la gestión de personas y existencia o no de nuevas prácticas institucionales, se observó una valoración favorable que alcanzó un $71 \%$. Dichas cifras se debieron principalmente y tal como se mencionó en apartados anteriores, por las labores que en sus inicios la DNSC y en específico la SDDP, tuvo con los jefes de servicios y analistas, enfocado en un rol de acompañamiento de las jefaturas de recursos humanos. Sin embargo, la puesta en marcha de los Convenios de Asesoría en Gestión de Personas (CAGP) en 2013 orientados a implementar capacidades de gestión y el Instructivo Presidencial sobre Buenas Prácticas Laborales en Desarrollo de Personas en el Estado 2015 que comienza a instalar cambios y prácticas de gestión que contribuyan a avanzar hacia un empleo público coherente con la definición de Empleo Decente formulada por la OIT son aspectos centrales para analizar las estadísticas obtenidas . Norma Fernández Sánchez-Encargada División Gestión y Desarrollo de Personas, Ministerio de Economía, Fomento y Turismo indicó ...Es una asesoría técnica, es una asesoría técnica fuerte pero en ningún momento, y a lo mejor es una de las cosas que adolece, de que muchas de sus propuestas faltan de un respaldo de modificación técnica, perdón, legal, no técnica, legal. Entonces, en ese sentido yo creo que ellos están al debe. Ahora bien, los resultados generales de este ámbito posicionan al Servicio Civil con un $71 \%$ lo que se traduce en que la asesoría brindada ha generado nuevas prácticas institucionales o al menos cambios en la gestión de personas.

En cuanto a las acciones de asesoría que durante el último año ha implementado la SDDP, destaca la orientación y el plan estratégico de trabajo que se ha definido en función del rol de la DNSC en el cumplimiento del Instructivo Presidencial 2015, ya que dicho documento, entrega un mandato al Servicio Civil para asesorar y otorgar apoyo experto a los Servicios Públicos en la implementación, definiendo funciones de monitoreo y elaboración de reportes de avance. Rodolfo Cuevas Pinto- Jefe de Departamento de Gestión de Personas, Ministerio de Vivienda y Urbanismo indicó... hoy día el instructivo te establece un estándar mínimo, un estándar mínimo de decir desde aquí la idea es construir y poder avanzar, en el intertanto que hay muchas cosas que nosotros tenemos ya implementadas, ya? y nosotros claramente ya comenzamos a pulir la política, a aspirar a la calidad porque el marco mínimo lo tenemos. De acuerdo a lo anterior, se destaca como un aspecto la diferenciación de avances que existe en los SPAC respecto al desarrollo de gestión de personas. En lo relativo a las prácticas implementadas, se visualizó que efectivamente se generaron prácticas que quedaron en los servicios públicos asociados principalmente a los PMG relacionados a recursos humanos, como el de evaluación de desempeño y de capacitación, introduciendo a modo general, en los SPAC, un modelo de gestión por competencia. En definitiva, el "acompañamiento o asesoría" se definió por parte de los entrevistados como un acompañamiento técnico, pero que considera un espacio también para los servicios, para el ajuste interno en la implementación de dichos cambios y la adecuación a la realidad de cada servicio. 
De modo similar se comentó sobre las prácticas vinculadas con desarrollo de gestión de personas, evidenciando que el Instructivo Presidencial 2015 da una mirada a la gestión de personas que no es la que ha venido dando el Servicio Civil que era un modelo. En el Servicio Civil el anclaje de la gestión de personas esta teóricamente en un modelo de los Convenios de Asesoría en Gestión de Personas (CAGP) en 2013 o el instructivo presidencial, que consideró avanzar en ejes y estos ejes son derechos laborales, ambientes laborales, etc. Lo anterior, fue un costo para los SPAC al momento de tomar el plan trienal y desarrollarlo, respecto al enfoque que debían seguir de acuerdo al modelo teórico o los ejes, el enfoque a utilizar, la mirada teórica o la mirada de los ejes, fue una dicotomía que tuvieron que enfrentar. Sin embargo, se destacó el apoyo del Servicio Civil para poder acomodar y anclar ambos lineamientos.

Como se ha dicho, existe una valoración positiva en este ámbito, sin embargo se evidenció que las valoraciones desfavorables y que alcanzan un $19 \%$, no significan necesariamente falta de gestión por parte de la DNSC, todo lo contrario, se concluye que existen aspectos que las diferentes jefaturas y analistas evidencian como aspectos débiles que deben ser fortalecidos por la DNSC, pero bajo una mirada de colaboradores estratégicos. Se constató también que para las jefaturas y analistas, cobra relevancia al interior de las instituciones los aspectos relacionados con gestión de personas y, en ello, la labor que realiza la DNSC es crucial, toda vez que releva la gestión de recursos humanos a las altas jefaturas y posiciona a un nivel estratégico la necesidad de implementar mejoras Norma Fernández Sánchez-Encargada División Gestión y Desarrollo de Personas, Ministerio de Economía, Fomento y Turismo indicó... cuando la jefatura del servicio está presente, sabe que esto se está haciendo, se ha comprometido también con esto, va a ser mucho más fácil porque va a haber oreja de que algo se está haciendo. Y esta vinculación que se hizo, esta triangulación, recursos humanos, jefe de servicio, jefe superior del servicio en este caso con nosotros, es importantísimo porque los jefes de servicio escucharon de primera fuente lo que la Subsecretaria quiere en materia de recursos humanos nuestro.

A continuación, se presenta la percepción respecto a la temática relacionada con el impacto de los ciclos políticos en la implementación de buenas prácticas laborales en los SPAC. Acerca de la temática indicada, se analizaron aspectos relacionados con el impacto de la esfera del mundo político en la gestión pública. A su vez, se observó la implicancia o no de factores que surgen producto de la interacción de ambas esferas en la implementación de buenas prácticas laborales.
El marco de acción del Servicio Civil resguarda la gestión de la Administración Pública de la esfera del mundo político, considerando la existencia y convivencia de ambas esferas. Por ello, es relevante observar los resultados obtenidos, ya que existe una tendencia positiva, alcanzando un $60 \%$ de apreciaciones favorables. Ahora bien, respecto al impacto de los ciclos políticos en la implementación de buenas prácticas laborales y considerando que existe una convivencia entre lo técnico y lo político, se constató que para las jefaturas de recursos humanos y analistas, dicho contexto técnico y político también debe considerar hasta donde se puede avanzar en estas buenas prácticas, ya que se reconoció por parte de los entrevistados que debe existir también un espacio para la autoridad de cada servicio. Se constató, que un elemento central es el compromiso y la voluntad política del jefe de servicio o la autoridad. El jefe de servicio debe manifestar que estos temas son relevantes para su gestión y son los que se van a abordar en el período de su mandato, ya que son temas que implican tiempo y recursos, que implican además rediseño de las áreas o de los servicios propiamente, siendo temas que revisten cierto grado de complejidad en su diseño y ejecución.

Asimismo, la premisa de que no se excluya ni enajene el componente político de la gestión del Servicio Civil y en el entendido de que es fundamental contar con el apoyo y voluntad de los jefes de servicios, es que la gestión de asesoría y acompañamiento del Servicio Civil a los jefes de servicio, por ejemplo, las reuniones de socialización del Instructivo Presidencial de 2015, fueron efectuadas con la presencia del Director del Servicio Civil convocando en la mayoría de los casos y dirigidas a los jefes de servicio y autoridades. Lo anterior, se enfoca en la gestión estratégica que realiza la DNSC en la perspectiva de que la mirada de recursos humanos se tiene que relevar a un nivel estratégico, bajo la lógica de que la gestión de personas debe reconocerse como un sistema integrado de gestión, cuya finalidad básica es la adecuación de las personas a la estrategia de la organización para así generar la producción de resultados acordes con los objetivos institucionales. Hasta ahora, se constató que en muchos servicios se concibe el área de gestión de personas o recursos humanos como un área de apoyo, pero que en la mayoría de los SPAC adolece de una mirada estratégica.

Como se revisó en apartados anteriores, en este ámbito se evidenció que la DNSC ha desarrollado en lo que respecta a la SDDP la convergencia, de la implementación y experiencia, como un patrón que se ha convertido en su estrategia, superponiendo la noción de convergencia a patrones formados mediante fuerzas externas o necesidades internas, siendo el verdadero aprendizaje organizacional, el 
que combina la reflexión con los resultados (Garrido, 2010). Considerando lo anterior, es que se constató que un conjunto de razones técnicas, políticas, culturales y clientelares, tanto internas como del contexto, tienden a generar fuertes incompatibilidades en la organización y en el funcionamiento del Servicio Civil y, por lo tanto, profundos impactos sobre la Gestión de Personas. Se evidenció a su vez mediante el $30 \%$ de valoración desfavorable, que diferentes períodos de Gobierno, otorgaron diferentes lineamientos y también dieron distinto niveles de importancia y prioridad a la gestión de personas. $\mathrm{Al}$ respecto, Oscar Villagra, Encargado de Asociaciones de Funcionarios- Ministerio de Agricultura indicó...en la administración pública convive lo técnico y lo político, entonces, eso es un tema que ha salido aquí tanto en la instalación de mesas y en esto del instructivo con respecto hasta donde se puede avanzar en estas buenas prácticas en un contexto técnico-político donde hay un espacio también que dejar a la autoridad, porque esto es política, para la discrecionalidad y en eso yo creo que ahí todavía nos falta un poco y le falta un poco...". Lo anterior, se debe considerar como un contexto que reviste cierto nivel de riesgo para la gestión del Servicio Civil, en el entendido de que el espacio que actualmente ocupa lo político para la gestión de personas, es fluctuante y no permite asegurar cambios que permanezcan en el tiempo. Ello, se evidenció a través de la puesta en marcha del Instructivo Presidencial 2015 y la suspensión de firmas de los Convenios de Asesoría en Gestión de Personas (CAGP), varios entrevistados manifestaron cambio de lineamientos y que les costó adecuarse al cambio considerando lo que ya habían avanzado. Por lo que es importante tener en consideración, como el contexto político y los cambios de Gobierno impactan la propia gestión del Servicio Civil, dado que los SPAC entrevistados, si bien lo valoran positivamente, en el escenario de que la triangulación: jefe de recurso humano, jefe de servicio y DNSC es crucial y ha permitido generar cambios internamente en la organización, el espacio en el que fluctúan las decisiones relativas a la gestión de personas en el sector público, debe considerar aspectos que permitan que la SDDP implemente bases en la administración central del Estado (ACE) para evitar la acumulación de políticas de personas que responden a las necesidades del contexto o responden a voluntades políticas, pero que carecen de una base que asegure mejoras sustantivas en la gestión y desarrollo de personas.

Finalmente, se constató que existe una valoración positiva como cifran los datos, sin embargo, el $30 \%$ de evaluación desfavorable fue posible analizarlo mediante conversaciones fuera de la entrevistas y registradas en notas de campo. En dicho contexto, los entrevistados indicaron que efectiva- mente los ciclos políticos impactaban tanto positiva como negativamente, aludiendo que determinadas tendencias políticas se centraban más en algunos enfoques de gestión de personas, o bien no veían como prioritario este tema en sus agendas de gobierno. Si bien valoraron el Instructivo Presidencial 2015 como una oportunidad, también aludieron a las confrontaciones internas que deben enfrentar ellos con las autoridades de sus respectivos servicios para implementar políticas en gestión de personas. Por lo que, nuevamente el rol de la DNSC como un organismo asesor surge como un elemento central, los entrevistados reconocen que a la DNSC se le han entregado ciertas tareas de rectoría en la materia, pero se constató que éstas son atribuciones bastante parciales para lograr los cambios de fondo al interior de los SPAC.

\section{Factores a considerar en la implemen- tación de buenas prácticas laborales en los servicios públicos}

A continuación, se presenta la revisión conjunta que se efectuó de las valoraciones tanto por los entrevistados DNSC como por los SPAC entrevistados, a fin de desarrollar un análisis que contribuya a la valoración global de la DNSC, destacando aquellos factores comunes y disímiles entre ambos grupos de estudio. Mediante un estudio comparado de las estadísticas obtenidas, se obtuvo una panorámica general de la valoración hacia la DNSC en aspectos como estructura, recursos, conocimientos y capacidad de gestión, lo que permitió realizar una indagación e identificar factores que son considerados en la implementación de buenas prácticas laborales en los servicios públicos de la administración central. Asimismo, fue posible identificar valoraciones comunes en la percepción de aspectos referidos a la asesoría brindada por la DNSC, siendo la tendencia predominante una valoración favorable de ambas instancias de estudio (DNSC $40,6 \%$ y SPAC $45,1 \%)$.

En lo relativo al rol, el Sub Director de Desarrollo de Personas de la DNSC sintetizó aspectos que bajo su perspectiva le parecían trascendentales referidos a la gestión que realiza el equipo a su cargo y lo que le interesaba plasmar con su gestión, indicó...que fuimos un referente técnico, me interesa, en segundo orden pero me interesa. Que mantengamos ese rol de referente técnico me parece muy bien logrado de esta subdirección y que nos confiere a todos los servicios, para donde vamos y lo siento de verdad, que reconocen a los profesionales del área, eso es lo segundo. Y lo tercero quizás, que hayamos contribuido a avanzar de manera más homogénea y de manera más transversal, y la forma. 
Y me gustaría agregar un cuarto que tiene que ver con el espacio de participación y el cómo se hizo. De acuerdo a los datos obtenidos y a modo global, se constató que la asesoría técnica entregada por la DNSC era apreciada por los SPAC, junto con la capacidad profesional y expertiz en las materias de su competencia. Sin embargo, en lo que respecta al rol, se evidenció que existe una demanda por parte de la DNSC para ejercer funciones de rectoría. Sin este rol, indicaron, es difícil que los SPAC ejecuten iniciativas y mantengan en el tiempo mejoras en gestión de personas. Por parte de los servicios públicos entrevistados, fue visible también dicha necesidad, dado que para ellos, significaría un empoderamiento al interior de sus organizaciones, para relevar estos temas, su importancia y poder avanzar de acuerdo la normativa lo indique. Andrea Ampuero BelmarEncargada de Buenas Prácticas Laborales, Ministerio de Salud reflexionó en este punto... Es que hasta ahora el rol del Servicio Civil es más que nada, como un asesor de contenido, asesor normativo en la aplicación de las distintas directrices del ex código de buenas prácticas del 2006 y ahora con el instructivo presidencial. También se agregó a lo anterior, que un rol fiscalizador forlatelecería la gestión que pueden desarrollar, dado que habría cumplimientos que alcanzar y revisión de éstos, en la perspectiva de alcanzar avances y bases en común entre diversos SPAC.

Se estudió también la relación existente entre tipo de asesoría e implementación de buenas prácticas laborales en los servicios públicos, que sean producto de la gestión de la DNSC. Evaluando la contribución que se realiza a los SPAC, si bien generan directrices en el ámbito de políticas de personal, la contribución en lo relativo a las asociaciones gremiales es un nicho que se ha comenzado a fortalecer en los últimos años. El Sub Director de Desarrollo de Personas de la DNSC indicó ...Nosotros participamos de instancias de trabajo en conjunto que impulsó el Ministerio de Hacienda ya desde al año pasado que se instaló, tanto con la ANEF como con las mesas del sector público y participamos en esas instancias. Y ahí lo que se hace es levantar cuáles son las necesidades, ver las preocupaciones y problemáticas de los gremios en lo que tratamos de generar un plan de trabajo con ellos. Ahora, con el lanzamiento del instructivo presidencial muchas de esas temáticas ya están contenidas, por tanto el foco cambia más bien en volver a asociarnos con los gremios y poder tener instancias de discusión que es la etapa en la que estamos. Y la segunda línea de trabajo que es propia desde el SC con los gremios, es un trabajo súper fuerte que estamos haciendo de difusión en distintas organizaciones gremiales. Por lo que la colaboración en este sentido, apunta a ser también un aliado estratégico de jefes de servicio, al momento de asesorar y liderar mesas de trabajo con gremios, lo que sin duda contribuye a que se puedan adoptar lineamientos y medidas consensuadas en lo que respecta a políticas en desarrollo de personas en el Estado.

$\mathrm{Al}$ revisar las valoraciones desfavorables, (DNSC $34,4 \%$ y SPAC $38,2 \%$ ), por parte de la DNSC dichas evaluaciones se referían principalmente a sus propias debilidades internas o bien carencias normativas, que vislumbraban como factores que incidían negativamente en su gestión. Sin embargo, se constató que uno de los puntos críticos en la gestión de la DNSC tiene que ver también con el marco normativo, pero también con las regulaciones vigentes en lo que respecta a la administración de personal. Rodolfo Cuevas Pinto- Jefe de Departamento de Gestión de Personas, Ministerio de Vivienda y Urbanismo indicó... Me pasa, y me ha pasado en el plano personal y de algunas otras situaciones que he revisado que muchas veces cuando existe alguna duda en el concepto te dicen "pucha"nosotros te creemos esto, pensado esto, podríamos orientar nuestra respuesta a esto pero finalmente quien da la última palabra es Contraloría. Entonces, nos pasa que a lo mejor debiéramos haber hecho la pregunta directamente a Contraloría, me tienes un mes dándome vuelta en una incertidumbre para que finalmente me digas: pregúntale al señor de al lado, pero creo que han avanzado, he visto una orgánica distinta, han crecido orgánicamente y en cuanto a funcionalidades, han abarcado más temas. Por lo que la pertinencia de sus lineamientos y orientaciones, pierde peso, al considerar que los lineamientos y asesoría que entregan carece también de la mirada normativa, en lo que está permitido efectuar de acuerdo lo indica el derecho administrativo.

Si bien este estudio de caso, no profundiza acerca de estas cuestiones, es importante mencionarlas, dado que existe la necesidad de realizar modificaciones legales, pero también es factible explorar alternativas en función de la coordinación, colaboración de flujos de trabajo que puedan superar esta debilidad. En esta misma línea de análisis Andrea Ampuero Belmar- Encargada de Buenas Prácticas Laborales, Ministerio de Salud indicó ...El tema es que quizás, o lo que en algunas reuniones echamos de menos muchos de los asistentes de las instituciones, es que ellos pudieran tener un rol más fiscalizador de las acciones en las actividades, que sugieran, no tan solo de asesoría. A todas luces por tanto, se concluyó, que debe existir un empoderamiento para la DNSC en lo que respecta a la instalación de prácticas en desarrollo de personas, no poseerlo tenderá a la entrega de lineamientos, que al no ser monitoreados o bien, no se encuentran regulados, se pierdan en la gestión diaria que realiza cada servicio público. 
Ahora, esta mirada también tiene que ver con la colaboración y contribución desde la perspectiva de la coordinación que se puede lograr entre distintas áreas de gestión de personas. Jessica RubilarAnalista Encargada de Reclutamiento y Selección, Ministerio de Desarrollo Social puntualizó ... yo te diría que falta a lo mejor un asesoramiento de los temas, más discusión, más debate, a lo mejor mostrarnos otra mirada, la de los otros servicios, como están trabajando y poder agregarnos un plus porque si yo miro lo que están haciendo, como buena práctica digamos, el Ministerio de Justicia o algo así cierto, ehh, yo voy a optar por eso, a lo mejor darnos otra mirada, ser un poco más... En esta misma línea de análisis, Norma Fernández SánchezEncargada División Gestión y Desarrollo de Personas, Ministerio de Economía, Fomento y Turismo reflexionó ...lo único que adolece un poco (DNSC) es que, como todo servicio, sueña un poco y ehh, hay limitaciones que nos da el estatuto que difícilmente podemos vencer. Lo anterior, se evidenció que impacta en la eficacia y también continuidad de las políticas implementadas, dado que si bien se entregan lineamientos y desarrollan planes de trabajo al no ser regulados, se pierden. En este sentido, se constató que es un elemento crítico que afectaría en cierta medida la gestión exitosa en estas materias.

Ahora bien, al enfocarse en el actual modelo de negocio y conocer como es percibida la calidad de la asesoría, Andrea Ampuero Belmar- Encargada de Buenas Prácticas Laborales, Ministerio de Salud resaltó ...pero en general son bastante ágiles con las respuestas incluso considerando que son pocas personas que trabajan en estas asesorías para los servicios. En esta temática fue posible conocer distintas apreciaciones respecto de sus experiencias individuales, por ejemplo Oscar Villagra- Encargado de Asociaciones de Funcionarios, Ministerio de Agricultura ejemplificó ... el instructivo llega en enero y la instalación fue tardía, de hecho, hay una comunicación que nosotros tenemos con el Ministerio ...preguntando cuando va a llegar la metodología para implementar el plan trienal, y esto fue por ahí por marzo y esto recién llegó en abril...para mayo... entonces tuvimos solamente un mes para el desarrollo del plan trienal que había que entregarlo el 30 de junio. Entonces eso tiene que ver con esa capacidad que tiene el Servicio Civil para atender en este momento a la totalidad de los servicios públicos, que nosotros al ir un poquito más avanzados a lo mejor estábamos demandando más... "oye sabes que nosotros ya tenemos desarrollado esto a través de las mesas, estamos avanzando en políticas", "No es que el instructivo no pide políticas, pide buenas prácticas" Entonces nos dijo, bueno sigan trabajando así y el instructivo les va a servir como una carta gantt para avanzar algunos temas que ustedes ya tienen avanzados. De lo anterior fue posible conocer dos experiencia que cada analista tuvo con la DNSC, sin embargo, apunta también al ordenamiento interno con el que actúa la DNSC, en cuanto a la definición de tiempos y procesos de gestión de su orgánica y la interacción con sus usuarios. En lo relativo a las miradas mencionadas, son experiencias contrapuestas, no obstante, la homogeneización que busca alcanzar el SDDP con el instructivo presidencial 2015 topa con estas realidades diversas.

La DNSC como organización, es consciente que existen diferentes niveles de avances, por lo que el trabajo desplegado significó diversas cargas de trabajo, diversos enfoques por parte de los SPAC y también una flexibilidad y adaptabilidad a las distintas realidades de los servicios por parte de la DNSC, lo anterior, se constató es un aspecto muy bien logrado por la SDDP, se evidenció como durante estos años ha sido efectivo su posicionamiento como un socio estratégico de los analistas y también de las jefaturas, en orden a avanzar en políticas e impulsar mejoras en desarrollo de personas.

\section{Conclusiones y Recomendacio- nes}

Como se indicó, el principal objetivo de esta investigación fue realizar un diagnóstico de la asesoría brindada por la DNSC y se estudió como dicha asesoría influyó en la consolidación de buenas prácticas laborales en los servicios públicos de la administración central del Estado. Considerando entonces los alcances indicados para la realización de esta investigación, se pudieron obtener resultados útiles en diversos aspectos.

En primer lugar, se concluyó que la asesoría que brinda la DNSC en gestión de personas permite la creación de políticas laborales en los SPAC, pero sin asegurar el desarrollo sostenido y sistemático de reformas relativas a la carrera funcionaria en el Estado. Lo anterior, se fundamenta en que si bien la DNSC utilizó modelos de sistemas de recursos humanos para orientar la gestión de personas, en específico el Modelo de Ciclos Temporales (MCT), dicho modelo genérico fue de cierta utilidad a la hora de explicar y enmarcar los avances y cambios alcanzados en estructura y políticas de los sistemas de recursos humanos de los SPAC. No obstante, se constató que rasgos propios de cada uno de los contextos internos de las reparticiones públicas, con frecuencia, tuvieron mayor fuerza a la hora de implementar o no reformas en lo relativo a política en desarrollo de personas. 
En segundo lugar, se constató que la estrategia de gestión y modelos de negocios de la DNSC en desarrollo de personas, ha respondido en gran medida a los contextos políticos y sociales, lo que si bien permitió que su gestión se adecuara a las necesidades del entorno, la ausencia de lineamientos rectores generó un apilamiento de iniciativas y reformas en desarrollo de personas. Lo anterior, se fundamenta en los cambios en las formas de asesoría impulsadas por la DNSC, a través de los Convenios de Asesoría en Gestión de Personas y su estancamiento y cambio producto de las instrucciones contenidas en el Instructivo Presidencial 2015.

En tercer lugar, se concluyó que la asesoría brindada por la DNSC es altamente valorada por lo SPAC que han trabajado con ellos. Reconociendo que se ha hecho un trabajo en conjunto y que les ha permitido fortalecer la gestión interna que efectúan analistas y jefes de unidades de recursos humanos. Lo anterior, se fundamenta en la instalación de diversos instructivos, manuales y procesos generados a partir de la generación de los CAGP, PMG relacionados con capacitación, como también manuales de buenas prácticas laborales, trabajos con gremios de empleados públicos, todas instancias propiciadas por la DNSC a través de la SDDP, pero que se encuentran en distintos niveles de avance y desarrollo.

En cuarto lugar, se evidenció que si bien la normativa regula y modula el comportamiento de los distintos actores políticos en el entendido de que el funcionamiento de la DNSC resguarda la gestión de la administración pública de la esfera del mundo político, más no excluye ni enajena un componente del otro, es que se hace necesario observar el control de los gestores por otros actores sociales y que de dicha relación se generen prácticas clientelares. Lo anterior se fundamenta en el descontento organizacional originado a través de los procesos de ascensos y despidos los que no obedecen a patrones comunes en los SPAC, otorgando un nivel amplio de discrecionalidad a los decisores, en materias que deben tener lineamientos rectores de una instancia superior como es la DNSC.

En consecuencia, existen debilidades en la planificación y consecución de objetivos relativos a los modelos de gestión desarrollados por la DNSC y, en específico de la SDDP desde su creación. Dichos niveles de avance y consecusión de objetivos en la actualidad son parciales y dísimiles en las diversas reparticiones públicas. Junto con ello, se evidenció la disparidad existente en cada SPAC en lo relativo a sus orgánicas internas en gestión de recursos humanos. Si bien existen criterios comunes en base a lo que regula la normativa en la materia, existen espacios de gestión que dan lugar a la discrecionalidad de analistas y jefaturas, que en términos generales se pudo constatar carecen de lineamientos específicos emanados desde la DNSC, sino que responden más bien a experiencias y demandas internas de cada organismo. Junto con ello, se visibilizó la ausencia de coordinación entre los mismos SPAC, a fin de compartir experiencias, avances y situaciones en común.

En otro orden de ideas, surge la necesidad también de fortalecer las actuales mesas de trabajo y negociación con las asociaciones gremiales, vinculando a los actores claves para la toma de decisiones, en el entendido de que una adecuada canalización de demandas a través de los canales institucionales, tenderá a la disminución de conflictos y permitirá el fortalecimiento de protocolos de acuerdo en torno a dar respuesta efectivas a las demandas levantadas por los gremios. Actualmente la DNSC cumple un rol en la articulación de los protocolos de acuerdo firmados entre el Ministerio de Hacienda, Ministerio del Trabajo y Asociación Nacional de Empleados, sin embargo, se evidenció que es un avance incipinete y que requiere ser fortalecido como instancia de conversación entre los gremios y el Gobierno.

Finalmente, se comprobó que el modelo de gestión de la DNSC combina elementos como la confianza y el mérito, siendo un modelo particular en América Latina, este posicionamiento lo ha logrado principalmente por el funcionamiento del Sistema de Alta Dirección Pública, no obstante se evidenció que el trabajo desarrollado en materias de políticas de desarrollo de personas ha sido parcial, siendo un desafío para la DNSC asumir una labor de rectoría en materias de políticas de desarrollo de personas. Rol rector que necesariamente debe ir aparejado de una arquitectura institucional que lo contenga. En síntesis, la DNSC ha logrado constituirse como una agencia especializada en materias para la gestión de las personas en el Estado, ha logrado alcanzar posicionamiento como una instancia asesora en materias de carrera funcionaria. Sin embargo, el modelo de asesoría y gestión implementado, adolece de aspectos que permitan a los servicios públicos pasar de un paradigma burocrático de administración de personal a la consolidación de procedimientos enfocados en la gestión y desarrollo de personas. Se constató una debilidad del Servicio Civil para cumplir función de rectoría en gestión de personas de la administración central del Estado. Por lo que la asesoría que brinda la DNSC en gestión de personas permite la creación de políticas laborales en los SPAC, pero sin asegurar el desarrollo sostenido y sistemático de reformas relativas a la carrera funcionaria. Lo anterior, es un desafío para dicha repartición pública, en el objetivo de preservar y desarrollar una administración profesional en el Estado. 


\section{Recomendaciones}

Actualmente, existen diversas versiones sobre el rol y la contribución que efectúa la DNSC en cuanto a su gestión en la implementación de políticas y buenas prácticas laborales en desarrollo y gestión de personas en el sector público. En efecto, una de las propuestas de este estudio es mantener el rol de asesoría a los SPAC y reorientarlo a la capacitación, al ser un aspecto bien logrado por la SDDP de la DNSC, en el entendido de que los servicios públicos que han recibido su asesoría valoran la contribución que ésta ha tenido tanto en la formación de capacidades como en el empoderamiento alcanzado al interior de cada repartición pública de algunos procesos en gestión de personas, junto con el desarrollo parcial de procedimientos relativos a la carrera funcionaria. Sin embargo, se hace imprescindible definir el rol de la DNSC en lo que respecta al ámbito de desarrollo de personas, orientando su rol a un rol rector en estas materias y fiscalizador del cumplimiento de las instrucciones que imparte, más que sólo mantener el acompañamiento y asesoría. Este estudio de caso propone también fortalecer aspectos relativos a la planificación estratégica por parte de la SDDP, bajo un modelo de gestión sistematizado que fortalezca procesos y desarrolle control de gestión efectivo, que defina plazos y productos, en el corto, largo y mediano plazo, con el objeto de establecer procedimientos atingentes a la realidad de cada servicio público, junto con observar la capacidad operativa y de recursos con la que cuenta.

No obstante lo anterior, sería insuficiente desarrollar los elementos mencionados sin considerar también el fortalecimiento y la coordinación interministerial a objeto de que los actores presentes en el desarrollo de una política laboral enfocada en la profesionalización de la administración pública estén adecuadamente coordinados. A esto se suma, la apremiante necesidad de contar con los recursos presupuestarios, humanos y técnicos necesarios para llevar a cabo el desarrollo de políticas laborales consistente en la administración pública. Es por ello, que se recomienda observar y considerar como lecciones aprendidas los avances logrados por el Sistema de Alta Dirección Pública, como un referente en la implementación de mejoras en políticas laborales en el Estado y que fue desarrollado como un caso nacional y por la propia DNSC.

Luego, el fortalecimiento de las actuales mesas de trabajo y negociación con las asociaciones gremiales, vinculando a los actores claves para la toma de decisiones y el fortalecimiento de protocolos de acuerdo en torno a dar respuesta efectivas a las demandas levantadas por los gremios es un aspecto que la DNSC debe continuar desarrollando y for- talecer, para así consolidar su posicionamiento en estas materias y contribuir al desarrollo exitoso de mejoras que contribuyan al desarrollo laboral de los SPAC.

Ahora bien, el tema de estudio posee variadas aristas que si bien son abordadas por las recomendaciones indicadas, dichas sugerencias se han enfocado en el fortalecimiento del actual modelo de gestión de la DNSC a través de la SDDP para continuar desarrollando las funciones que desde su creación se le han encomendado. No obstante, cabe precisar que dada la variedad de situaciones indagadas, la multiplicidad de realidades presentes y la complejidad que presupone la ejecución de medidas de acuerdo a la orgánica actual de funcionamiento de la DNSC en estas materias, es que se sugiere realizar un diagnóstico crítico de los actuales mecanismos que contribuyen a la ejecución efectiva, sistemática y continua de mejoras sustantivas en desarrollo de políticas laborales en el Estado, a fin de revisar los puntos críticos de funcionamiento de la DNSC en estos ámbitos e indagar nuevos modelos de gestión que contribuyan a alcanzar los objetivos propuestos, considerando que para el cumplimiento efectivo de reformas sustantivas en esta materia, más que contar con un rol rector y de fiscalización, se requiere contar con un modelo de gestión que permita la flexibilización, adecuación al contexto y generación de redes que permitan articular y ejecutar iniciativas que por sus características deben ser abordadas con un sentido estratégico, ágil y dinámico, que no necesariamente responden a las actuales organizaciones que promueve y contiene el Estado. Para ello, se propone también la creación de estudios e investigaciones en profundidad que argumenten la necesidad y orienten el fortalecimiento de una relación integral entre la DNSC y los SPAC $\mathrm{y}$, desde esa perspectiva, es que el presente estudio pretende haber efectuado una contribución que sea útil para profundizar futuros esfuerzos que releven la importancia de fortalecer el desarrollo laboral de los funcionarios públicos como un aspecto central en el fortalecimiento de los Estados modernos.

\section{Referencias}

Bardin, L. (2002). Análisis de Contenido. Akal Universitaria., Madrid, España.

Dirección Nacional del Servicio Civil (2013). Barómetro de la Gestión de Personas.

Dirección Nacional del Servicio Civil (2015). Plan Estratégico Sud Dirección Desarrollo de Personas 2014-2018. Presentación institucional no publicada. 
Echebarría, K. (2005). La Gestión de los Recursos Humanos en el Sector Público tendencias y desafíos. División Estado, Gobernabilidad y Sociedad Civil. Banco Interamericano de Desarrollo.

Garrido, L. (2010). Inetaracción estratégica en la impementación de políticas Públicas: El caso de la nueva política de recursos humanos en el sector público chileno (2003-2006). Tesis doctoral, Universidad de Chile.

Gratton, L. (2001). Estrategias de Capital Humano: Como situar a las personas en el corazón de la empresa.

Longo, F. (2001). odernizar la gestión pública de las personas: los desafíos de la flexibilidad. Revista CLAD, (19).

Longo, F. (2004). La calidad de los sistemas de servicio civil en América Latina y el Caribe: una metodología de evaluación. Revista CLAD, (28).

Longo, F. (2005). Planificación estratégica y gestión de los Recursos Humanos. En Nuevos enfoques de la gestión de RRHH en las Administraciones Públicas.

Osgood, C., Suci, G., y Tannenbaum, P. (1957). The measurement of meaning. Univer. of Illinois Press.

Oszlak, O. (2002). Documento de Trabajo de la IV Reunión de Ministros de la Administración Pública y Reforma del Estado. Santo Domingo.

Oszlak, O. (2009). La Profesionalización del Servicio Civil en América Latina: Impactos sobre el proceso de democratización. En La Democracia de ciudadanía: una agenda para la construcción de ciudadanía en América Latina. OEA-PNUD.

Palomar, A. (2000). Derecho de la Función Pública. Régimen jurídico de los funcionarios públicos. Madrid.

Sampieri, R., C., F., y P., B. (2006). Metodología de la Investigación. McGraw-Hill., lztaalapa. México.

Sekiou, L. (2001). Gestion des ressources humaines. De Boeck Supérieur. 